\title{
Safety and Feasibility of Magnetic Seizure Therapy (MST) in Major Depression: Randomized Within-Subject Comparison with Electroconvulsive Therapy
}

\author{
Sarah H Lisanby*, ${ }^{*, 2}$, Bruce Luber ${ }^{1,2}$, Thomas E Schlaepfer ${ }^{4}$ and Harold A Sackeim ${ }^{1,2,3}$ \\ 'Magnetic Brain Stimulation Laboratory, Department of Biological Psychiatry, New York State Psychiatric Institute, New York, NY, USA; \\ ${ }^{2}$ Department of Psychiatry; College of Physicians and Surgeons, Columbia University, New York, NY, USA; ${ }^{3}$ Department of Radiology, College of \\ Physicians and Surgeons, Columbia University, New York, NY, USA; ${ }^{4}$ Psychiatric Neuroimaging Group, Department of Psychiatry, University \\ Hospital Bern, Switzerland
}

Magnetic seizure therapy (MST) is a novel means of performing convulsive therapy using rapidly alternating strong magnetic fields. MST offers greater control of intracerebral current intensity than is possible with electroconvulsive therapy (ECT). These features may result in a superior cognitive side effect profile for MST, while possibly retaining the efficacy of ECT. The objective of this study was to determine whether MST and ECT differ in seizure characteristics, and acute objective and subjective cognitive side effects. A total of I0 inpatients in a major depressive episode referred for ECT were enrolled in this randomized, within-subject, double-masked trial. Seizure threshold was determined with MST and ECT in the first two sessions of a course of convulsive therapy, with order randomized. The remaining two sessions consisted of suprathreshold stimulation with MST and ECT. A neuropsychological battery and side effect rating scale were administered by a masked rater before and after each session. Tonic-clonic seizures were elicited with MST in all patients. Compared to ECT, MST seizures had shorter duration, lower ictal EEG amplitude, and less postictal suppression. Patients had fewer subjective side effects and recovered orientation more quickly with MST than ECT. MST was also superior to ECT on measures of attention, retrograde amnesia, and category fluency. Magnetic seizure induction in patients with depression is feasible, and appears to have a superior acute side effect profile than ECT. Future research will be needed to establish whether MST has antidepressant efficacy.

Neuropsychopharmacology (2003) 28, I852-1865, advance online publication, 16 July 2003; doi:10.1038/sj.npp. 1300229

Keywords: electroconvulsive therapy; magnetics; major depressive disorder; major depressive episode; seizure; transcranial magnetic stimulation

\section{INTRODUCTION}

Despite the unparalleled efficacy of electroconvulsive therapy (ECT) in severe depression, its use is limited by its cognitive side effects that decrease its acceptance by patients and some clinicians (American Psychiatric Association, 2001; Lisanby et al, 2000; Prudic et al, 2000). The antidepressant properties of ECT and its effects on cognition are uncorrelated (Lerer et al, 1995; Lisanby et al, 2000; McElhiney et al, 1995; Sackeim, 1992) and considerable progress has been made in altering the ECT technique to maintain efficacy while reducing cognitive side effects. Nonetheless, the forms of ECT with the most well-

*Correspondence: Dr SH Lisanby, Department of Biological Psychiatry, New York State Psychiatric Institute, 1051 Riverside Drive, Unit 126, New York, NY I0032, USA, Tel: + I 212543 5568, Fax: + I 212543 6056, E-mail: SHL24@columbia.edu

Received II October 2002; revised 13 April 2003; accepted 02 May 2003

Online publication: I4 May 2003 at http://www.acnp.org/citations/ Npp05 | 403376/default.pdf established efficacy/side effect profile still result in a substantial side effect burden (Bailine et al, 2000; Delva et al, 2000; McCall et al, 2000; Sackeim et al, 1993, 2000b).

A growing body of evidence suggests that ECT electrical dosage and the intracerebral pathway of the electrical current are critical for determining both efficacy and side effects (Abrams et al, 1991; McCall et al, 2000; Nobler et al, 1994; Sackeim et al, 1986a,b, 1996, 1993, 2000a,b). Depending on the combination of stimulus intensity and electrode position, antidepressant response rates with ECT vary from below 20 to $70 \%$ or higher (McCall et al, 2000; Sackeim et al, 1993, 2000a, b). Right unilateral (RUL) ECT results in less intense and persistent adverse cognitive effects than bilateral (BL) ECT, but RUL ECT can either be highly ineffective or effective, depending upon the electrical dosage relative to the seizure threshold $(\mathrm{Ng}$ et al, 2000; Sackeim et al, 1987a, 1993, 2000b). Supporting these clinical findings, independent alterations in regional brain activity, as reflected in regional cerebral blood flow (rCBF) (Awata et al, 2002; Nobler et al, 1994), cerebral metabolic rate for glucose (Henry et al, 2001; Nobler et al, 2001), and 
electroencephalographic (EEG) measures (Sackeim et al, 1996, 2000a), correlate with the efficacy and objective cognitive side effects of ECT. For example, antidepressant response has been linked to increased EEG $\delta$ power and decreased $\mathrm{rCBF}$ in prefrontal regions, while retrograde amnesia for autobiographical memories has been linked to increased left frontotemporal EEG $\theta$ power (Luber et al, 2000; Sackeim et al, 1996, 2000a). These findings suggest that a technique that can target the induced current to regions implicated in antidepressant response, while sparing regions implicated in adverse cognitive effects, would maintain efficacy and have a superior side effect profile. This advantage would be accentuated if such a technique also offered better control not only over intracerebral current pathways (ie targeting of regions) but also over intracerebral current density.

The use of an electrical stimulus to induce seizures is a fundamental limitation in refining convulsive therapy. The high impedance of the skull (Driscoll, 1970; Geddes and Baker, 1967; Rush and Driscoll, 1968) shunts the bulk of the electrical stimulus away from the brain. An unknown proportion of the electrical stimulus results in neuronal depolarization, with the shunting producing a nonfocal, widespread intracerebral current distribution regardless of electrode placement. Measurements in humans (Law, 1993; Smitt and Wegener, 1944) and monkeys (Hayes, 1950) of shunting across the scalp and skull range from $80-97 \%$. The degree of shunting varies considerably among individuals, due to individual differences in skull thickness and anatomy (Driscoll, 1970). Skull inhomogeneities, for which there are also considerable individual differences, result in further regional variability in current density even when the anatomic positioning of electrodes is consistent across patients (Hayes, 1950; Law, 1993; Sackeim et al, 1994; Weaver et al, 1976). For example, Law (1993) measured resistance in bone plugs from 20 regions of the human skull and found a 16-fold range $(1360-21400 \Omega / \mathrm{cm})$ in resistivity values (Law, 1993). Thus, inherent in the application of an external electrical stimulus that must traverse the scalp, skull, and cerebral spinal fluid to reach the brain, is the highly variable and widespread distribution of current and little control over the intracerebral current density.

Stimulating the brain with repetitive transcranial magnetic stimulation (rTMS) could obviate some of the limitations of electrical stimulation, by inducing intracerebral current noninvasively using rapidly alternating magnetic fields (Barker et al, 1985; Pascual-Leone et al, 1993). The scalp and skull are transparent to magnetic fields, removing a major source of individual differences in the intensity and spatial distribution of intracerebral current density. In addition, depending principally on coil geometry, the magnetic field can be spatially targeted in cortical regions, offering further control over intracerebral current paths (Brasil-Neto et al, 1992; Maccabee et al, 1991, 1990; Mills et al, 1992). However, the electrical field induced by rTMS is capable of neural depolarization at a depth extending to about $2 \mathrm{~cm}$ below the scalp (ie gray-white matter junction), so direct effects are limited to the cortex (Epstein, 1990). Measurements in nonhuman primates with intracerebral multicontact electrodes support the hypothesis that rTMS-induced current and the resulting seizure are more focal than those obtained with ECT (Lisanby et al, in press, 1998a, b; Lisanby and Sackeim, 2002). Thus, magnetic stimulation holds the promise of more precise control over current paths and current density in neural tissue.

A growing number of studies have examined the antidepressant effects of subconvulsive levels of rTMS (for reviews, see Burt et al, 2002; George et al, 1999; Lisanby and Sackeim, 2000; Wassermann and Lisanby, 2001). While prior work had shown that subconvulsive levels of ECT are not effective (Gottesfeld et al, 1944; Hargrove et al, 1953; Ulett et al, 1956), it was not known whether the same would hold true for rTMS, particularly since a single electrical train was applied for subconvulsive ECT while repeated trains within a session were given with subconvulsive rTMS. Indeed, recent work with subconvulsive rTMS challenges the view that a seizure is necessary for brain stimulation techniques to exert antidepressant effects (George and Wassermann, 1994; Sackeim, 1994), much as recent work with ECT challenged the dogma that a seizure was sufficient for efficacy (McCall et al, 2000; Sackeim et al, 1993, $2000 \mathrm{a}, \mathrm{b})$. A recent meta-analysis of 23 comparisons of subconvulsive rTMS relative to a sham control found that 16 had a positive effect (effect size $\geqslant 0.3$ favoring active rTMS). Across these comparisons, the size of the pooled effect size was moderate to large. The majority of studies have demonstrated that rTMS results in a greater degree of improvement than sham. A small percentage of studies were negative (Garcia-Toro et al, 2001; Lisanby et al, 2001b; Loo et al, 1999; Manes et al, 2001; Martin et al, 2002; Mosimann et al, 2002). Many of these studies were underpowered to detect clinically meaningful effects, and were complicated by the concomitant use of antidepressant medications. Larger and more definitive trials are underway to address important remaining questions regarding optimal rTMS dosage and treatment frequency, region to target and the focality of stimulation, patient population most likely to remit, and so on.

Seizures have been elicited with rTMS, both inadvertently (in normal volunteers and two patients with depression, Conca et al, 2000; Pascual-Leone et al, 1993; Wassermann et al, 1996) and intentionally (in epileptic patients in an attempt to identify seizure focus, Claussen et al, 1995; Dhuna et al, 1991; Hufnagel and Elger, 1991; Hufnagel et al, 1990; Tassinari et al, 1990). These reports suggested that seizure induction is related to the extent that magnetic stimulus intensity exceeds the individual's motor threshold (MT) (ie minimum intensity required to elicit a movement of a specified amplitude in a distal hand muscle), and led to the development of guidelines to ensure that standard applications of rTMS remain subconvulsive (Wassermann, 1998). Thus, on both conceptual and empirical grounds, it should be possible to develop devices capable of seizure induction, despite the anticonvulsant effects of the anesthetic medications typically used during convulsive therapy.

We recently reported the deliberate induction of tonicclonic seizures in rhesus monkeys under general anesthesia, using a custom modified magnetic stimulator with heightened output capabilities (Lisanby et al, 2001a). Clinical application of magnetic seizure induction as a form of convulsive therapy has so far been limited to a report of a single case (Lisanby et al, 2001c). This study examined the feasibility of magnetic seizure therapy (MST) in depressed patients, and contrasted magnetically induced seizures with 
conventional ECT in acute cognitive side effects and electrophysiological characteristics. Based on the fact that the induced current is limited to a small volume of the cortex, it was hypothesized that MST would have a superior cognitive side effect profile compared to ECT. Given a more focal induction of seizure activity, it was also hypothesized that MST would result in weaker ictal EEG expression.

\section{METHODS}

\section{Subjects}

This study was conducted under an Investigational Device Exemption from the FDA, and was approved by the Institutional Review Board of the New York State Psychiatric Institute, in accord with the Helsinki Declaration. A total of 10 inpatients between the ages of 21 and 65 years participated after providing informed consent. The patients were referred for treatment with ECT and met DSM-IV criteria for a major depressive episode based on the Structured Clinical Interview for Diagnosis. Exclusion criteria included neurological disorder or history of head trauma, current unstable or serious medical illness, pregnancy/breast-feeding, presence of implanted electronic devices, and a score on the Mini-Mental Status Exam of less than 24 (out of 30 ). Patients could remain on psychotropic medications as clinically indicated, but doses were held constant over the 4 study sessions and benzodiazepine use was limited to no more than $3 \mathrm{mg}$ per day of lorazepam equivalents. Patients received routine pre-ECT medical and laboratory workup with no modifications required for MST.

\section{Study Design}

All patients received a course of convulsive therapy (three sessions per week), in which MST was given in two of the first four sessions and ECT was administered in the remaining sessions. In the first two sessions, the seizure threshold was titrated using the ascending method of limits procedure (Sackeim et al, 1987b) (with ECT and MST seizure threshold titrated on separate days, and order randomized). For both ECT and MST, fixed titration schedules were used in which stimulations were given with progressively longer train duration until a seizure was obtained. The remaining two sessions consisted of suprathreshold stimulation (with ECT and MST on separate days, order randomized). Condition order was randomly assigned, with all orders of MST and ECT represented. Patients, clinical raters, and neuropsychology technicians were masked to condition order.

\section{Motor Threshold}

MT was defined as the minimum magnetic intensity needed to elicit a threshold EMG response $(50 \mu \mathrm{V}$ in peak-to-peak amplitude) in a target muscle in five out of 10 trials using single-pulse TMS administered to the contralateral primary motor cortex. MT of the left first dorsal interosseous muscle was determined at baseline prior to the induction of anesthesia, using a round coil $(9 \mathrm{~cm}$ diameter, Magstim Company Limited, Whitfield, Wales, UK) centered over the vertex. This was performed in the awake patient in order to minimize time under anesthesia and avoid the effects of repeated anesthetic administration on seizure threshold.

\section{Anesthesia}

Atropine ( $0.4 \mathrm{mg}$ i.v.) was given $2 \mathrm{~min}$ prior to anesthesia induction. Methohexital $(0.75 \mathrm{mg} / \mathrm{kg})$ and succinlycholine $(0.75 \mathrm{mg} / \mathrm{kg})$ were the intravenous anesthetic agents. These doses were held constant across the four study sessions. Patients were oxygenated (positive pressure, $100 \% \mathrm{O}_{2}$ ) from anesthetic administration until return of spontaneous respiration.

\section{EEG Acquisition}

Seizure duration was monitored with BL frontal-mastoid EEG channels, as well as motor manifestations using the cuff technique. EEG electrodes were slotted to reduce heating due to rTMS (Roth et al, 1992). Electrophysiological data were acquired with electrically isolated bioamplifiers (SA Instruments, San Diego, California), bandpass filtered from 0.3 to $100 \mathrm{~Hz}$, and digitized at $1 \mathrm{kHz}$. Artifacts were removed off-line using an interactive editing program by a technician masked to intervention condition. Artifact-free data were subjected to a fast Fourier transformation (FFT), using $1 \mathrm{~s}$ epochs with overlapping $0.5 \mathrm{~s}$ windows, starting immediately after the termination of the MST or ECT stimulus and continuing until $15 \mathrm{~s}$ after seizure termination. The average power in each of four frequency bands $(\delta 1-$ $3.5 \mathrm{~Hz}, \theta 3.5-7.5 \mathrm{~Hz}, \alpha 7.5-12.5 \mathrm{~Hz}, \beta 12.5-29.5 \mathrm{~Hz}$ ) was calculated for each channel, separately for the ictal and postictal periods. For both the ictal and postictal periods, global power was defined as the sum power across the four frequency bands.

\section{Magnetic Seizure Therapy}

Repetitive TMS results in a high-frequency clicking noise during coil discharge. To protect hearing, as well as to maintain the mask, earplugs were worn by patients during both MST and ECT sessions. As is a standard protective measure for ECT (Morris et al, 2002), a bite-block was inserted immediately prior to seizure elicitation to protect the teeth. It was noted, however, that MST did not produce the marked jaw contraction as typically seen with ECT, suggesting less stimulation of the masseter muscle. MST was administered with a modified magnetic stimulator, using 16 booster modules (Magstim Company Limited, Whitfield, Wales, UK) instead of four. The peak-induced magnetic field was $2 \mathrm{~T}$ at the coil surface, according to the operating manual. The pulse had a dampened cosine waveform with a width of $500 \mu$ s (twice as wide as commercial rTMS devices). The stimulator was capable of administering up to $60 \mathrm{~Hz}$ for $6.6 \mathrm{~s}$ at $100 \%$ of maximal stimulator output. Three coil types (7 cm diameter figure-8, 9 and $12 \mathrm{~cm}$ double cone, and $9 \mathrm{~cm}$ round) and three scalp positions (RUL-site F6 of the International 10-20 EEG system, midline frontal-site $\mathrm{Fz}$, and vertex-site $\mathrm{Cz}$ ) were used to determine their relative efficiency in seizure induction. Coils were positioned in the optimal orientation to elicit an MEP from the right motor strip. This orientation corresponds to a posterior to anterior current flow (Brasil-Neto et al, 1992). For MST, the 
stimulation intensity was held constant at $100 \%$ maximal output of the device, independent of MT, and pulse frequency $(40-60 \mathrm{~Hz})$ and train duration $(0.5-8.0 \mathrm{~s})$ were varied to determine magnetic seizure threshold. The suprathreshold MST sessions were all given at maximal stimulator output (400 pulses).

\section{Electroconvulsive Therapy}

ECT electrode placement was determined purely on clinical grounds. Nine patients received RUL ECT and one patient was given BL ECT, using the d'Elia and bifrontotemporal placements, respectively. A Spectrum 5000Q ECT device (MECTA Corp., Lake Oswego, OR) was used. The ECT pulse width was $0.5 \mathrm{~ms}$, approximately the width of the MST stimulus. After ECT threshold titration, subsequent ECT treatments were administered at six times the seizure threshold for RUL ECT and 2.5 times the threshold for BL ECT, following the procedures described elsewhere (Sackeim et al, 2000b). After the fourth session in this protocol, patients received open treatment with ECT, as clinically indicated.

\section{Neuropsychological Assessments}

A neuropsychological battery sampling multiple cognitive domains was administered by a masked rater at baseline and immediately before and after each of the four test sessions (see Sackeim et al, 1986b, 1993; for a complete description of the 'Treatment Effects Battery'). Alternate forms of each task were used on each testing occasion, with assignment randomized. Prior to each session, orientation was assessed with a 10-item inventory. The patients then memorized a set of 12 words, four geometric shapes, four nonsense shapes, and eight emotionally neutral faces. Retention of the items was tested immediately following stimulus presentation, assessing both recall and recognition for words and recognition for the shapes and faces. The assessments of immediate retention provided a baseline for the postictal evaluation of verbal and nonverbal retrograde amnesia. Following the seizure, once patients opened their eyes on command, orientation was tested until the criteria for full recovery were met or $90 \mathrm{~min}$ had elapsed. No patient required $90 \mathrm{~min}$ or longer at any session. After orientation recovery, attention was assessed using three visual cancellation tasks (letter, geometric shape, and nonsense shape). Retrograde amnesia was then assessed using recall (word) and recognition (word, shape, and face) of the stimuli presented prior to the session. Semantic memory, assessed using visual confrontation naming and verbal confrontation naming, is resistant to the effects of ECT (Prudic et al, 1994), thus these measures of anomia were included as control tasks. A source memory task (Shimamura and Squire, 1987) was administered that simultaneously assessed memory for the temporal order of sentences in two lists and item recognition (whether or not the sentence had been presented). While both item retrieval and source identification are thought to involve the prefrontal cortex to some degree, several lesion and imaging studies suggest that memory for source (context) is more heavily prefrontally mediated, while item recognition is more reliant upon temporal lobe contributions (Cabeza et al, 2000, 1997;
Janowsky et al, 1989; Nyberg et al, 1996). Verbal fluency for letters and categories were tested using standard methods (Benton, 1983; Goodglass and Kaplan, 1983). While both letter and category fluency are thought to involve the prefrontal cortex, recent work suggests that category fluency also recruits left temporal regions, more so than letter fluency (Gourovitch et al, 2000; Kitabayashi et al, 2001; Pihlajamaki et al, 2000).

At baseline and on the afternoon following each session, anterograde verbal memory was assessed using the Buschke Selective Reminding Test (12 trials with 12 unrelated words, Buschke, 1973) Following a 2-h delay, the complete procedure was repeated (Sackeim et al, 2000b). Anterograde nonverbal memory was assessed with respect to the memory of a complex figure, and included reproduction after 3 and 20 min (Lezak, 1995).

\section{Clinical Assessments}

The 32-item Columbia ECT subjective side effects schedule (Sackeim et al, 1987c) was administered by a masked rater at baseline and on the afternoon following each of the four study sessions. This study was not specifically designed to assess the therapeutic efficacy of MST, since all subjects received both ECT and MST. The average final Hamilton Rating Scale for Depression (HRSD, 24-item) score following the entire course of MST and ECT (which averaged $11.3 \pm 4.7$ sessions) was $9.4 \pm 4.2$, and all patients showed substantial improvement.

\section{Data Analysis}

Sample characteristics are reported as mean \pm SD for continuous variables and as percentages for discontinuous variables. The intervention conditions were compared in terms of effects on neuropsychological performance using repeated measures analyses of covariance (ANCOVAs). In the ANCOVAs, intervention condition (MST vs ECT) and dosage condition (threshold $v s$ suprathreshold) were within-subject factors, with condition order (four levels) as a between-subjects factor, and baseline performance on the particular neuropsychological measure as the covariate. Significant main effects were followed up with post hoc ANOVAs and paired $t$-tests, as appropriate. Tests of significance were two-tailed, with an $\alpha$ of 0.05 . Time to achieve reorientation, seizure duration, ECT seizure threshold, and EEG power values were subjected to log transformation to achieve normal distributions. Retrograde amnesia for the recall and recognition of material presented immediately prior to the intervention was expressed as the percentage of items not recalled or recognized following the intervention relative to the number remembered prior to the intervention.

Subjective side effect reports were analyzed separately for their occurrence and severity. In addition to analyses on individual side effect items, three a priori categories were defined, following the methods previously validated (Devanand et al, 1995; Sackeim et al, 1987c). The physical side effects grouping included complaints of headache, nausea, dry mouth, muscle pain, and other aches and pains. The cognitive grouping included reports of confusion and memory problems. The mood-related grouping included 
reports of enjoying breakfast, enjoying lunch, feeling more active, and feeling less slowed down.

\section{RESULTS}

\section{Subjects}

A total of 10 inpatients (three male) in a major depressive episode participated. Three patients had bipolar disorder and one of these patients also presented with the psychotic subtype. The mean age of the sample was $46.7 \pm 10.0$ years (range 30-59). The average baseline HRSD score (24-item) was $27.5 \pm 6.5$ (range 18-36) and MMSE was $28.6 \pm 1.6$ (range 25-30). One patient had a secondary diagnosis of obsessive-compulsive disorder, and three patients had a history of substance dependence, now in remission. One of the 10 patients left the study after her first intervention, which was threshold MST. Although the drop in her HRSD after this intervention was only from 21 to $16(23.8 \%)$, the patient felt substantial improvement and was discharged.

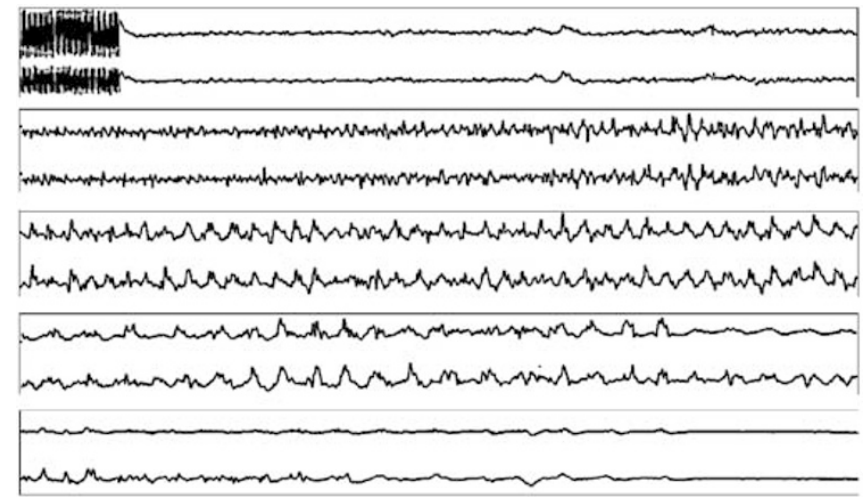

Figure I Bifrontal EEG recorded during MST. The parameters of stimulation were $40 \mathrm{~Hz}, 100 \%$ of maximal stimulator output, $6.3 \mathrm{~s}$ duration administered with a round coil placed on the vertex. A generalized tonicclonic seizure lasting $57 \mathrm{~s}$ by motor manifestations was elicited.
Five of the 10 patients remained free of psychotropic medications throughout the study period. Of the remaining five patients, two received neuroleptics, one was given an anticonvulsant, and two were taking antidepressants. In all cases, doses of these psychotropic and other concomitant medications were held stable throughout the study. Ondansetron $4 \mathrm{mg}$ i.v. was given to two patients and ketorolac tromethamine $30 \mathrm{mg}$ i.v. was given to three patients to manage acute postintervention nausea and headache, respectively.

\section{Seizure Induction with MST and ECT}

Seizures were successfully induced with MST in all 10 patients. Tonic-clonic seizures similar to those seen with conventional ECT (Figure 1) were elicited with MST with both threshold level and suprathreshold magnetic stimulation. MST seizure threshold averaged $268 \pm 105$ pulses (range 100-400), and with an upper limit to device output of 400 pulses per train, four patients had thresholds at the maximal train duration (Table 1). Further, given that the minimum MST seizure threshold was 100 pulses, no patient could be treated at six times threshold, unlike suprathreshold stimulation with RUL ECT. All patients could be treated with ECT at their designated suprathreshold electrical dosage.

The intervention conditions (MST vs ECT) and the dosage conditions (threshold vs suprathreshold) were compared submitting the variables in Table 1 to repeated measures ANOVAs. There were no significant differences in anesthetic dosage across the intervention sessions. Given the differences in the unit of measurement for assessing threshold with MST (number of pulses) and ECT (charge, $\mathrm{mC}$ ), comparisons could not be made. Across dosage conditions, MST-induced seizures had shorter EEG and motor durations than ECT-induced seizures. Post hoc comparisons indicated that MST-induced seizures had shorter duration within each dosage condition and type of manifestation (EEG or motor) (all $P$ 's $<0.04$ ).

Table I MST and ECT Seizure Induction Sessions

\begin{tabular}{|c|c|c|c|c|c|c|}
\hline \multirow[b]{2}{*}{ Task } & \multicolumn{2}{|c|}{ Threshold } & \multicolumn{2}{|c|}{ Suprathreshold } & \multicolumn{2}{|c|}{ Main Effects (F-test) ${ }^{a}$} \\
\hline & MST & ECT & MST & ECT & Condition & Dosage \\
\hline \multicolumn{7}{|l|}{ Anesthetic agents } \\
\hline Atropine (mg) & $0.4 \pm 0.0$ & $0.4 \pm 0.0$ & $0.4 \pm 0.0$ & $0.4 \pm 0.0$ & 0 & 0 \\
\hline Methohexital (mg) & $58.0 \pm 2.9$ & $72.9 \pm 15.6$ & $57.2 \pm 3.2$ & $62.8 \pm 5.6$ & 2.19 & 0.49 \\
\hline Succinylcholine (mg) & $52.0 \pm 2.5$ & $72.1 \pm 18.5$ & $52.2 \pm 2.8$ & $52.2 \pm 2.8$ & 0.99 & 0.99 \\
\hline \multicolumn{7}{|l|}{ Stimulus dosage } \\
\hline MST (pulses) & $268.1 \pm 105.0$ & - & $382.7 \pm 49.0$ & - & - & $9.75^{*}$ \\
\hline $\mathrm{ECT}(\mathrm{mC})$ & - & $64.0 \pm 84.7$ & - & $261.3 \pm 174.9$ & - & 42.78****** \\
\hline \multicolumn{7}{|l|}{ Seizure duration } \\
\hline Motor (s) & $39.3 \pm 17.6$ & $56.7 \pm 9.1$ & $34.1 \pm 10.3$ & $47.3 \pm 12.0$ & | $6.84 * *$ & $6.38^{*}$ \\
\hline EEG (s) & $40.9 \pm 22.2$ & $101.0 \pm 43.8$ & $49.5 \pm 52.4$ & $74.4 \pm 35.5$ & $23.82 * * *$ & 2.06 \\
\hline \multicolumn{7}{|l|}{ Hemodynamic changes } \\
\hline Change in heart rate (bpm) & $24.4 \pm 18.3$ & $39.4 \pm 55.9$ & $49.8 \pm 60.5$ & $37.8 \pm 21.6$ & 0.05 & 1.19 \\
\hline Change in systolic blood pressure & $17.3 \pm 13.2$ & $31.7 \pm 19.3$ & $26.2 \pm 19.4$ & $32.9 \pm 26.8$ & 2.83 & 0.74 \\
\hline Change in diastolic blood pressure & $28.1 \pm 22.3$ & $44.7 \pm 23.1$ & $35.5 \pm 22.5$ & $37.6 \pm 46.6$ & 1.22 & 0.05 \\
\hline
\end{tabular}

${ }^{a}$ All $F$ tests with degrees of freedom $(I, 8) ; N=10$ for threshold MST and $N=9$ for all other conditions.

$* P<0.05, * * P<0.01$, **** $P<0.001$. 
ECT typically results in pronounced hemodynamic changes, with prominent ictal elevations in heart rate and blood pressure (American Psychiatric Association, 2001; Prudic et al, 1987). Both MST and ECT demonstrated significant increases in heart rate as well as systolic and diastolic blood pressure. There were no significant differences among the intervention or dosage conditions (Table 1), suggesting that the magnitude of the sympathetic discharge due to catecholamine release was similar to that of MST and ECT.

\section{Quantitative Ictal and Postictal EEG with MST and ECT}

The repeated measures ANOVA on power in the four frequency bands for the left and right EEG channels, with intervention and dosage conditions as additional withinsubject factors, yielded a main effect of intervention, $\mathrm{F}_{1,7}=43.51 ; P<0.0003$ (Figure 2). For each frequency band, MST-induced seizures had less robust ictal expression than ECT (all $P$ 's $\leqslant 0.007$ ). In contrast to the analyses on seizure duration, there were no effects involving dosage condition and laterality of EEG electrodes.

A similar repeated measures ANOVA was conducted on power in the four frequency bands in the immediate postictal period. Postictal EEG expression was suppressed to a greater extent with ECT than MST, $\mathrm{F}_{1,7}=13.26 ; P<0.008$. As expected with RUL ECT, there was greater postictal suppression in the right relative to the left EEG channel, as reflected in the main effect of laterality, $\mathrm{F}_{1,7}=7.09 ; P<0.03$. In addition, there was significant intervention by dosage condition, $\mathrm{F}_{1,7}=7.09 ; P<0.03$. Post hoc analyses indicated that suprathreshold seizures produced with ECT showed greater postictal suppression than suprathreshold MST seizures, $F_{1,7}=47.31 ; P<0.0001$, while $M S T$ and ECT seizures at threshold dosage did not differ in postictal suppression, $\mathrm{F}_{1,7}=0.95 ; P<0.4$. This pattern held for all frequency bands (Figure 2). There was also a significant

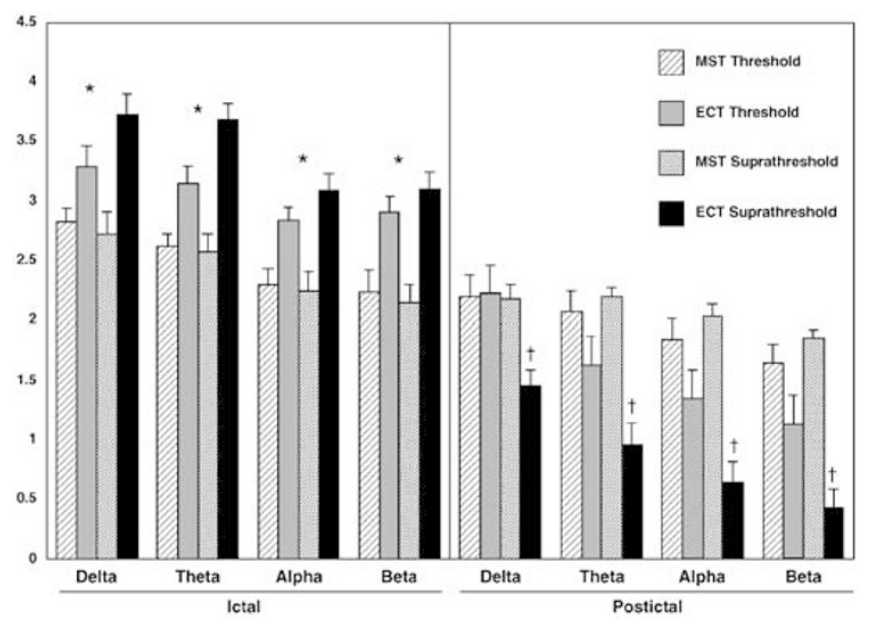

Figure 2 Ictal and postictal EEG expression in five frequency bands with MST and ECT revealed a main effect of condition $(P<0.0003$ for ictal, $P<0.008$ for postictal). *Less robust ictal expression with MST, all condition differences significant ( $P$ 's $<0.007)$. †Less robust postictal suppression with suprathreshold levels of MST, all differences significant (post hoc t-test P's $<0.005$ ). Threshold MST and ECT did not differ in postictal suppression. $N=10$ for threshold MST, and $N=9$ for the other three conditions. interaction between the intervention and frequency band, $\mathrm{F}_{3,21}=8.47 ; P<0.0007$. Post hoc analyses indicated that the greater postictal suppression with ECT relative to MST was significant for the $\theta, \alpha$, and $\beta$ frequency bands (all $P$ 's $<0.02)$, but not for $\delta\left(\mathrm{F}_{1,7}=1.94 ; P=0.21\right)$.

\section{Seizure Threshold and MT}

The various coils and coil placements could be ordered in terms of their efficiency in seizure induction. Relative to the focal coils, the nonfocal coils required less intense stimulation to produce seizures (ie they were more efficient) than the focal coils. The large round coil was more efficient than the double cone coil, which in turn was more efficient than the figure- 8 coil. Indeed, the figure-8, the most focal coil, could not produce a seizure at maximum stimulator output. The coil placements also appeared to differ in efficiency, with the vertex placement being the most efficient, the right prefrontal the least efficient, and the midline prefrontal placement intermediate.

Seizure thresholds with MST and with ECT were not correlated $\left(r_{8}=-0.12 ; P>0.75\right)$. Excluding the single patient who received BL, ECT increased the correlation coefficient, but it remained nonsignificant $\left(r_{7}=0.41\right.$; $P>0.3$ ). The TMS MT averaged $55 \pm 8 \%$ (range $46-70 \%$ ) of maximal stimulator output. There was a trend for MT to correlate with MST seizure threshold $\left(r_{8}=0.63 ; P<0.06\right)$, but no relationship between MT and ECT $\left(r_{8}=-0.37\right.$; $P>0.32$; when excluding the single BL case $r_{7}=-0.41$; $P>0.32$ ). The absence of a relationship between ECT seizure threshold and MT could have been due to the limited variability in ECT seizure threshold in this sample, where seven of nine patients had identical ECT seizure threshold $(32 \mathrm{mC})$. Nonetheless, there was substantial variability in MT, suggesting that MT and ECT seizure thresholds were in fact uncorrelated, unlike the relationship between MT and MST.

\section{Subjective Side Effects}

MST sessions were well tolerated with a high level of patient acceptance and no serious adverse events. Analyses of the composite scales of the Columbia ECT subjective side effects schedule revealed a main effect of intervention $\left(\mathrm{F}_{1,3}=11.96 ; P<0.04\right)$ with a trend for a condition by dosage interaction $\left(\mathrm{F}_{1,3}=8.24 ; P<0.06\right)$. Results were unchanged when leaving out the BL ECT case $\left(\mathrm{F}_{1,3}=16.38 ; P<0.02\right)$. Post hoc analysis indicated that the composite scores for physical side effects were lower following MST than ECT $\left(\mathrm{F}_{1,3}=43.56 ; P<0.007\right)$. This advantage for MST in physical side effects was seen in both the threshold $\left(t_{7}=5.6 ; P<0.0008\right)$ and suprathreshold conditions $\left(t_{6}=2.45 ; P<0.05\right)$. Exploratory analyses of individual items on this scale produced main effects of intervention for the incidence and severity of headache $\left(\mathrm{F}_{1,5}=7.86 ; P<0.03\right.$ for incidence and $\mathrm{F}_{1,5}=7.35 ; P<0.04$ for severity), subjective memory problems $\left(\mathrm{F}_{1,8}=6.4\right.$; $P<0.04$ for incidence and $\mathrm{F}_{1,8}=5.33 ; P<0.05$ for severity), and muscle aches $\left(\mathrm{F}_{1,5}=18.85 ; P<0.007\right.$ for incidence and $\mathrm{F}_{1,5}=6.65 ; P<0.05$ for severity). The differences between the interventions all favored MST. 


\section{Acute Cognitive Side Effects}

Disorientation and inattention. Patients recovered full orientation more quickly following both threshold and suprathreshold MST than they did following ECT $\left(\mathrm{F}_{1,7}=6.83 ; \quad P<0.03 ;\right.$ and $\mathrm{F}_{1,7}=34.34 ; \quad P<0.0006$ when excluding the BL ECT patient) (Figure 3 ). This effect was significant for both threshold $\left(t_{8}=5.9, P<0.0004\right)$ and suprathreshold $\left(t_{8}=4.5, \quad P<0.002\right)$ conditions. Patients were both faster and more accurate in completing the visual cancellation tasks following MST than ECT (Figure 4), with main effects of intervention for speed $\left(\mathrm{F}_{1,4}=19.49\right.$; $P<0.01)$ and for accuracy $\left(\mathrm{F}_{1,5}=19.45 ; P<0.007\right)$ across the three cancellation tasks. The patient receiving BL ECT did not complete this task, thus the results refer to the unilateral ECT cases only. The advantage of MST in both speed and number of correct responses was seen for both the threshold $\left(\mathrm{F}_{1,6}=6.56 ; \quad P<0.04\right.$ for speed; $\mathrm{F}_{1,6}=6.48$; $P<0.04$ for accuracy) and suprathreshold conditions $\left(\mathrm{F}_{1,4}=7.28 ; \quad P<0.05\right.$ for speed; $\mathrm{F}_{1,6}=8.1 ; \quad P<0.04$ for accuracy). These differences were not at the expense of a higher rate of false positive responses. MST and ECT did not differ in commission errors on the cancellation tasks.

Retrograde amnesia. Both ECT and MST induced significant amnesia for the recall of verbal material presented immediately prior to the intervention, and there were no main effects of intervention or dosage (Table 2). However, there was an interaction between intervention and dosage conditions in the recognition of this verbal material $\left(\mathrm{F}_{1,2}=46.53 ; P<0.02\right)$. Threshold ECT and MST did not differ in recognition performance, while suprathreshold MST was superior to suprathreshold ECT $\left(\mathrm{F}_{1,5}=6.35\right.$;

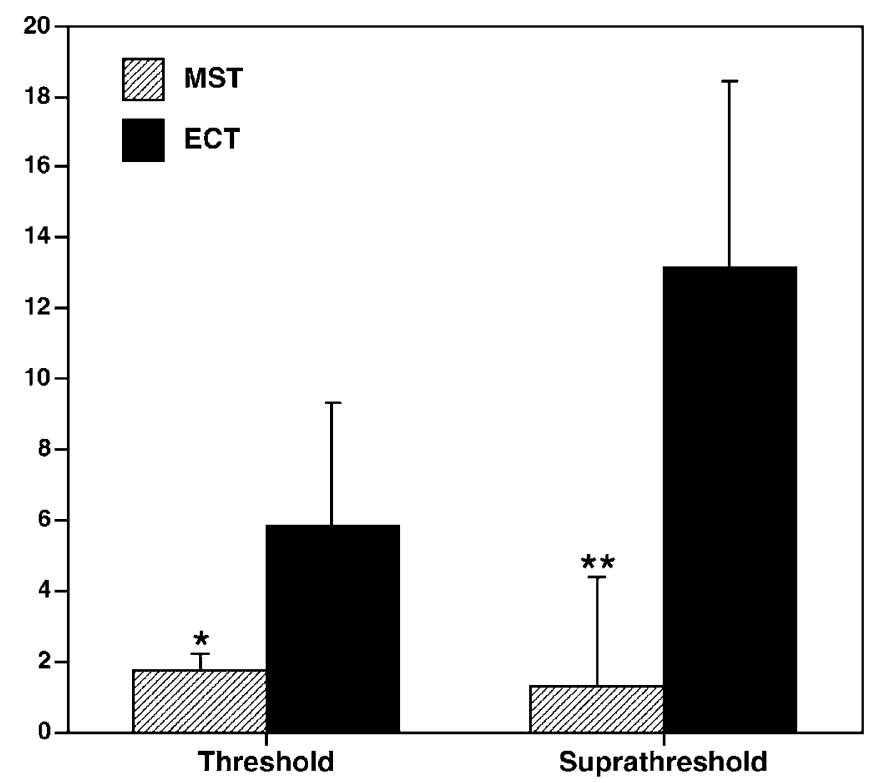

Figure 3 Median time in minutes to recover full orientation following threshold and suprathreshold MST and ECT. There was a main effect of condition $\left(F_{1,7},=6.83 ; P<0.03\right)$, and no order or dosage effects. * Reorientation following threshold MST was faster than threshold ECT $\left(t_{8}=-5.92 ; P<0.004\right)$. *** Reorientation following suprathreshold MST was faster than suprathreshold ECT $\left(t_{8}=-4.52 ; \quad P<0.001\right) . \quad N=10$ for threshold MST, and $N=9$ for the other three conditions.

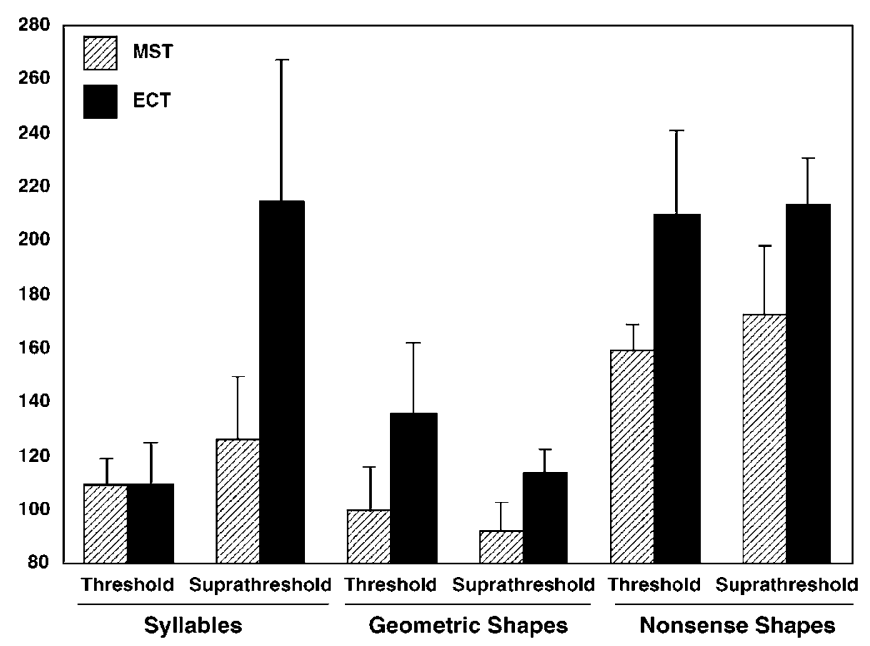

Figure 4 Visual attention immediately after MST and ECT as assessed by speed of performance on three cancellation tasks (syllables, geometric shapes, and nonsense shapes). Patients were faster following MST than ECT, with a main effect of condition $\left(F_{1,4}=19.49, P<0.01\right) . N=9$ for threshold MST, and $N=8$ for the other three conditions.

$P<0.05)$. This effect was no longer significant when excluding the patient who received BL ECT.

MST and ECT did not differ in retrograde amnesia for the geometric and nonsense shapes presented prior to the intervention (Table 2). Repeated measures ANCOVAs on recognition of face stimuli revealed main effects of intervention $\left(\mathrm{F}_{1,2}=72.99 ; \quad P<0.01\right.$ for neutral faces; $\mathrm{F}_{1,2}=48.0 ; P<0.02$ for affective faces). The patient receiving BL ECT did not complete this task, thus the results refer to the unilateral ECT cases only. Neutral face recognition was superior following suprathreshold MST than suprathreshold ECT $\left(t_{6}=2,65 ; P<0.04\right)$. The recognition of affective faces was superior following threshold MST than threshold ECT $\left(t_{8}=3.83 ; P<0.005\right)$, but the difference failed to reach significance for the suprathreshold conditions (Table 3 ).

Anterograde amnesia for sentence recognition and list order. Recognition of newly learned sentences showed a main effect of intervention $\left(\mathrm{F}_{1,4}=8.11 ; P<0.05\right)$ and a condition by dosage interaction $\left(\mathrm{F}_{1,4}=10.87 ; P<0.03\right)$. Results were unchanged on removing the BL ECT patient $\left(\mathrm{F}_{1,4}=7.84 ; P<0.04\right)$. Post hoc analyses indicated that threshold MST and ECT did not differ in sentence recognition, but there was superior performance following suprathreshold MST than suprathreshold ECT $\left(t_{5}=2.80\right.$; $P<0.04$; Table 3 ). There were no group differences in the false positive rate for sentence recognition, and no differences in identification of the sentences as belonging to List one or List two.

Verbal fluency and naming. Fluency for letters and categories showed a main effect of dosage condition $\left(\mathrm{F}_{1,3}=343.00 ; P<0.03\right)$ and a trend for a main effect of intervention $\left(\mathrm{F}_{1,3}=104.14 ; P<0.06\right)$. Category fluency was superior following suprathreshold MST than ECT $\left(t_{5}=3.06\right.$; $P<0.03$; unchanged when excluding the BL ECT case), but this difference failed to reach significance for threshold sessions (Table 3). MST and ECT did not differ significantly 
Table 2 Retrograde Amnesia Immediately Following MST and ECT ${ }^{\mathrm{a}}$

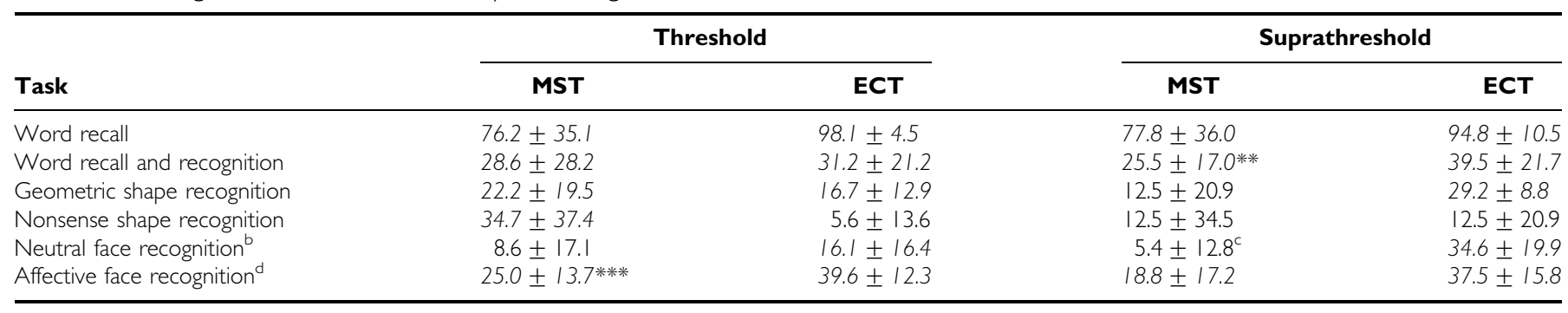

**Eess amnesia with suprathreshold MST than ECT, $t_{6}=2.47 ; P<0.05$

****Recognition of affective faces better following threshold MST than ECT, $t_{8}=3.83 ; P<0.005$.

${ }^{a}$ Percentage amnesia expressed as mean $\pm \mathrm{SD}$. Higher scores reflect worse performance. $N=10$ for threshold MST and $N=9$ for all other conditions (except $N=8$ for faces).

bMain effect of intervention favoring MST, $F_{1,2}=72.99 ; P<0.01$

'Less amnesia with suprathreshold MST than ECT, $t_{6}=2.65 ; P<0.04$

'Main effect of intervention favoring MST, $F_{1,2}=48.0 ; P<0.02$.

Values in italics differed from zero (all $P$ 's $<0.05$ ), indicating significant amnesia.

Table 3 Other Neuropsychological Tasks Immediately Following MST and ECT

\begin{tabular}{|c|c|c|c|c|}
\hline \multirow[b]{2}{*}{ Task } & \multicolumn{2}{|c|}{ Threshold } & \multicolumn{2}{|c|}{ Suprathreshold } \\
\hline & MST & ECT & MST & ECT \\
\hline Sentence recognition $(\max \text { score }=24)^{b}$ & $18.6 \pm 2.9$ & $18.0 \pm 3.4$ & $21.4 \pm 3.7 * * *$ & $15.8 \pm 3.1$ \\
\hline \multicolumn{5}{|l|}{ Verbal fluency } \\
\hline Letter & $14.2 \pm 6.2$ & $10.8 \pm 2.6$ & $15.4 \pm 4.7$ & $13.4 \pm 3.8$ \\
\hline Category ${ }^{c}$ & $17.2 \pm 4.0$ & $16.4 \pm 6.6$ & $27.0 \pm 4.5^{* * * * *}$ & $15.2 \pm 1.3$ \\
\hline
\end{tabular}

** Sentence recall better following suprathreshold MST than ECT, $t_{5}=2.80 ; P<0.04$.

****Category fluency better following suprathreshold MST than ECT, $t_{5}=3.06 ; P<0.03$.

a Means \pm SD. Higher scores reflect better performance. $N=10$ for threshold MST and $N=9$ for all other conditions.

bMain effect of intervention favoring MST, $F_{1,4}=8.1$ I; $P<0.05$.

${ }^{c}$ Trend for main effect of intervention favoring $M S T, F_{1,3}=104.14 ; P<0.06$.

in verbal fluency for letters. There were no differences in repetition errors or out-of-category responses between intervention or dosage conditions.

As expected, there was no difference between interventions in picture naming and word finding in response to abstract questions (Table 3).

\section{Short-Term Anterograde Amnesia}

There was an intervention by dosage condition interaction $\left(\mathrm{F}_{1,3}=41.26 ; P<0.008\right)$ in scores for reproduction of the complex figure. Following the 20 min delay, reproduction was worse following suprathreshold MST than ECT $\left(t_{6}=-3.36 ; P<0.02\right)$, while performance was nonsignificantly better following threshold MST than ECT (Table 4). This effect for suprathreshold MST remained significant after controlling for baseline performance and condition order $\left(\mathrm{F}_{1,4}=20.41 ; P<0.01 ; \mathrm{F}_{1,3}=114.9 ; P<0.009\right.$ excluding the BL ECT case).

MST and ECT did not differ in their short-term effects on verbal list learning (Table 4). There were no effects of intervention or dosage condition in total recall over the 12 trials at first or delayed presentation.

\section{Masking}

Best guess ratings following each intervention revealed that patients and clinical raters remained masked to the intervention (ECT $v s$ MST). Intervention was correctly identified by patients $64.9 \pm 48.4 \%$ of the time (not significantly different from chance), and by clinical raters $54.1 \pm 50.5 \%$ of the time (NS). However, the neuropsychological technician was able to correctly identify the intervention $75.7 \pm 43.5 \%$ of the time (binomial test, $P<0.001)$. Accuracy and confidence ratings of the neuropsychology technician's guess did not differ as a function of intervention or dosage. Average confidence in the guess by the neuropsychological technician, $3.5 \pm 1.3$ (corresponding to 'medium' on a 1-5 scale), was higher than patient or clinical rater confidence ratings $\left(t_{36}=2.38 ; P<0.02\right.$ for patient comparison, and $t_{36}=2.35 ; P<0.02$ for clinical rater comparison).

\section{DISCUSSION}

The major findings of this study are that deliberate induction of generalized seizures with MST is feasible in a clinical setting, and appears to be a well-tolerated method 
Table 4 Anterograde Amnesia Following MST and ECT ${ }^{a}$

\begin{tabular}{|c|c|c|c|c|}
\hline Task & \multicolumn{2}{|c|}{ Threshold } & \multicolumn{2}{|c|}{ Suprathreshold } \\
\hline \multicolumn{5}{|c|}{ Complex shape recall $(\max \text { score }=36)^{b}$} \\
\hline 3 min delay & $21.4 \pm 8.3$ & $17.1 \pm 8.5$ & $20.7 \pm 7.2$ & $24.1 \pm 7.3$ \\
\hline 20 min delay & $21.9 \pm 8.5$ & $16.6 \pm 8.3$ & $19.9 \pm 7.8 * * * *$ & $24.4 \pm 7.7$ \\
\hline Total recall after $2 \mathrm{~h}$ delay & $112.1 \pm 28.2$ & $106.8 \pm 24.5$ & $103.1 \pm 30.7$ & $110.7 \pm 30.9$ \\
\hline
\end{tabular}

aHigher scores reflect better performance, $N=10$ for threshold MST, $N=9$ for other conditions.

${ }^{\mathrm{b}}$ Treatment by dosage condition interaction in complex shape recall, $\mathrm{F}_{1,3}=41.26 ; P<0.008$.

***** Complex shape recall worse following suprathreshold MST, $t_{6}=-3.36 ; P<0.02$.

for performing convulsive therapy that merits further study. While both MST and ECT induced seizures, the techniques differed in subjective side effects, cognitive sequelae, and electrophysiological characteristics.

The acute side effect profile of MST was superior to ECT in several measures, including subjective side effects, orientation recovery, attention and some measures of anterograde and retrograde amnesia. With one exception, all the differences found between MST and ECT in side effects favored MST. Finding significant advantages for MST relative to ECT is especially noteworthy when considering both the modest sample size and the fact that the form of ECT used in this study $(0.5 \mathrm{~ms}$ pulse width in all cases, and RUL ECT in $9 / 10$ cases) has a particularly benign cognitive side effect profile compared to other forms of ECT administration. Results from an ongoing study contrasting the efficacy and side effects of ultra-brief pulse ECT indicate that this form of ECT has a substantially lower seizure threshold and significantly fewer cognitive side effects compared with conventional pulse width ECT (Sackeim et al, 2001).

The electrophysiological findings support the hypothesis that the mode of seizure induction (magnetic $v s$ electrical) alters the characteristics of the induced seizure. Quantitative analysis revealed that, compared to ECT, MST-induced seizures had less robust ictal EEG expression. Furthermore, although the extent of postictal bioelectric suppression did not differ when MST and ECT were administered at seizure threshold, suprathreshold MST produced less suppression than suprathreshold ECT. This difference, observed only with suprathreshold stimulation, may have been due to the inequality of the two interventions in dosage relative to threshold. Limitations in device output prevented the matching of suprathreshold MST stimulation to the extent to which electrical dosage exceeded threshold with ECT (six times the threshold for RUL and 2.5 times the threshold for the $\mathrm{BL}$ case).

The clinical significance of the electrophysiological differences between MST and ECT is unknown. It has been reported that certain ictal and postictal EEG changes, such as the degree of ictal expression and postictal suppression, are correlated with the efficacy of conventional ECT (Folkerts, 1996; Krystal et al, 1995; Nobler et al, 1993; Suppes et al, 1996). Whether these same relationships will pertain to MST is unknown. Importantly, recent work has called into question the classical relationship between these electrophysiological measures and clinical efficacy. Nobler et al (2000) found only weak relations between seizure expression and clinical outcome (Nobler et al, 2000). Ongoing work indicates that ultra-brief pulse RUL ECT lacks EEG characteristics formerly thought to be markers of effective treatment (Sackeim et al, 2001). This dissociation between electrophysiological markers and the clinical efficacy of ultra-brief pulse RUL ECT highlights the need for empirical evidence from a clinical trial to determine the clinical efficacy of MST and establish what EEG characteristics of MST-induced seizure, if any, are associated with the therapeutic effects of MST. Just as the lower dosage relative to threshold may have contributed to the differences between the suprathreshold interventions in electrophysiological effects, this dosage difference may have also influenced the differences in cognitive side effects. Indeed, for several neuropsychological measures, there were main effects of electrical dosage or interactions with intervention, supporting the importance of dosage in moderating cognitive effects. However, MST showed advantages relative to ECT when both were administered at low dosage, just above the seizure threshold (ie recovery of orientation, speed and accuracy of performance on attention tasks, nonverbal retrograde amnesia, and subjective physical side effects). This suggests that MST, as hypothesized, may have an intrinsically superior side effect profile compared to ECT.

The cognitive domains where ECT showed greater impairment than MST were generally those subserved at least partly by temporal lobe structures (ie memory for recent events, new list learning, category fluency, Gourovitch et al, 2000; Kitabayashi et al, 2001; Lezak, 1995; Pihlajamaki et al, 2000). In contrast, tasks that were more heavily dependent on prefrontal lobe function did not show differences between MST and ECT (eg memory for temporal order, verbal fluency for letters, Cabeza et al, 2000, 1997; Janowsky et al, 1989; Nyberg et al, 1996; Spreen and Strauss, 1998). These results support the view that MST has less impact than ECT on temporal lobe, and specifically the hippocampal, functioning due to its more localized intracerebral current distribution that is confined to the superficial cortex under the magnetic coil. It should be kept in mind, however, that multiple cortical locations were stimulated with MST in this study. Future studies comparing the effects of specific sites of seizure induction with MST could test the hypothesis that inducing current more focally 
in the prefrontal cortex will exert an effect on cognitive tasks that make strong demands on prefrontal function. Of note, modulation of functional activity in the prefrontal cortex has been linked to the antidepressant effects of ECT (Luber et al, 2000; Nobler et al, 2001, 1994; Sackeim et al, 2000a, 1996), thus the preservation of an impact on this region may be important for the potential therapeutic effects of MST.

MST was also superior to ECT in time to recover orientation. The specific mechanisms involved in this process are not well understood, but several have argued that disorientation following ECT represents a rapidly shrinking form of retrograde amnesia (Daniel et al, 1987; Sobin et al, 1995). Indeed, the duration of post-ECT disorientation predicts longer-term retrograde amnesia (Sobin et al, 1995). This would be compatible with the view that MST has less effect on temporal lobe structures. MST also exerted a marked advantage relative to ECT in measures of inattention. Inattention and neglect can be produced by lesions at multiple levels within corticolimbic reticular formation networks, including the prefrontal cortex, right parietal cortex, temporoparietal-occipital junction, cingulate gyrus, and subcortical regions such as the thalamus and mesoencephalic reticular formation (Heilman and Valenstein, 1993; Mesulam, 1985; Vallar, 1993). An advantage of MST in immediate postictal attention is consistent with MST having less impact on more posterior cortical and subcortical regions than ECT. While of clinical importance, the neuropsychological effects of MST and ECT only indirectly implicate differences between these interventions in their effects on regional brain function. Just as characteristic patterns of effects on regional brain function have been characterized for RUL and BL ECT using in vivo functional brain imaging Nobler et al, 1994; Silfverskiöld and Risberg, 1989), such studies are needed to determine the differential effects of MST and ECT on regional brain activity.

This study provided the first direct test of the supposed relationship between MT and the threshold for seizure with rTMS. MT is used to individualize the dosage of rTMS to reduce the risk of inadvertent seizure (Wassermann, 1998). MT is a measure of motor cortex excitability that can be reliably quantified. The relationship between MT and seizure threshold is not well understood. MT has been reported to be lower in epileptic patients (Reutens and Berkovic, 1992), but studies have failed to find a significant relationship between MT and seizure threshold as measured with ECT (Amiaz et al, 2001; Lisanby et al, 1997). The current study replicated the lack of association between MT and ECT seizure threshold. This is perhaps not surprising since ECT seizure threshold is partly determined by various anatomic factors related to scalp and skull thickness, impedance, and inhomogeneities-factors not relevant to the neural excitability of magnetic stimulation. It is more likely that MT is associated with individual differences in the threshold for seizures induced by MST, since in both instances the stimulation is magnetic and intracerebral current density is primarily dependent upon the distance from the stimulating coil rather than tissue composition and anatomic factors that determine the spatial distribution and degree of shunting of an externally applied electrical current. While the correlation between MT and MST achieved only trend-level significance, the power to detect significant associations between variables across subjects was highly limited by the small sample size. Indeed, ongoing work with a larger sample size of rhesus monkeys indicates a significant correlation between MT and MST seizure threshold (unpublished data). Support for a relationship between MT and magnetic seizure threshold has significant clinical importance for the subconvulsive applications of rTMS, where the goal is to avoid inadvertent seizure induction.

As this was the first clinical trial of MST in depressed patients, the cautious decision was made to only administer two MST sessions in the midst of a course of conventional ECT. This was performed out of ethical considerations since both efficacy and side effects of MST are unknown and there was the intent not to unduly delay the onset of antidepressant efficacy of ECT in these severely depressed patients. Therefore, the study design only permitted examination of the acute cognitive side effects of individual sessions, and not the cumulative or long-term cognitive side effects or the potential antidepressant properties of MST. Nonetheless, cognitive side effects are most severe in the acute postictal period (Daniel and Crovitz, 1983a,b; Sackeim, 1992). Treatment conditions that differ in shortand long-term cognitive side effects, such as RUL and BL ECT, have their most pronounced differences in acute postictal assessment (Sackeim et al, 2000b, 1993). Furthermore, it has been shown that some acute side effects predict the magnitude of long-term retrograde amnesia following ECT (Sobin et al, 1995). In essence, it has been argued that the long-term amnestic effects of ECT represent incomplete resolution of the acute cognitive side effects, and that treatment manipulations that reduce acute effects would likely have reduced long-term effects (Sobin et al, 1995).

Another consequence of this being the first clinical trial of MST in depressed patients, aside from a single case report, is that the methodology for seizure induction with MST in humans had to be worked out during the course of this trial. This required the use of multiple different stimulating coils and coil placements, implying the stimulation of different cortical regions which would be expected to result in differential cognitive and other effects. Since the sample size was small, it was not possible to control for this factor in analyses to determine how the coils compare. However, one factor that the various coil placement share and that distinguishes MST from ECT, is that the electric field induced by rTMS is confined to the superficial cortex, although it is recognized that postsynaptic effects will be present and differ as a function of the cortical site stimulated. Subsequent studies comparing the coil placements in their acute and long-term cognitive profile are indicated, and will be important to determine optimal MST technique.

As noted, the suprathreshold MST condition was close to (and in some cases the same as) the seizure threshold, potentially biasing the comparisons of the suprathreshold sessions in favor of MST. Nevertheless, the comparison between MST and ECT at threshold levels was matched for dosage by virtue of the seizure threshold titration procedure. The domains in which threshold doses of MST and ECT differed included subjective side effects, speed of orientation recovery, speed and accuracy on visual attention 
tasks, and recognition of affective faces. All differences favored MST. MST device development should focus on raising maximal stimulator output. This may be as relevant in ensuring optimal treatment with MST as it is established with ECT (Lisanby et al, 1996; McCall et al, 2000; Sackeim et al, 2000b, 1993). Coil design was another technical limitation of this study. The present generation of coils capable of focal stimulation was less efficient in inducing seizure than coils that intrinsically result in diffuse stimulation (nonfocal). To take advantage of precise spatial targeting with magnetic stimulation, new coils are needed that combine a focal stimulation pattern with sufficient field strength for reliable seizure induction.

Another limitation was that a large number of statistical comparisons were conducted in a small sample, without adjustment for their number. Since MST is a novel experimental procedure, intended for severely ill patients, this strategy was adopted to ensure that potential marked adverse effects of MST could be detected. In addition, the post hoc analyses comparing specific interventions were performed only after obtaining significant effects in omnibus tests. The within-subject design substantially decreased the variability in intervention-induced effects and likely was the key to the detection of intervention differences in this small sample. Given the significant clinical heterogeneity in this small sample, it will be important to replicate these effects in a larger and more homogeneous sample. There was a suggestion of inferior performance following MST compared to ECT on one cognitive task, delayed reproduction of the complex figure which is a measure of anterograde amnesia for nonverbal material. Further work in a larger sample will be needed to determine whether this represents a cognitive domain of special vulnerability to MST relative to ECT.

Although the neuropsychological raters were kept masked to the intervention condition, the 'best guess' questionnaire revealed that they could guess intervention assignment an average of $76 \%$ of the time with medium confidence. This may have biased the neuropsychological results in favor of MST, however, it would not be expected to affect the other measures (subjective side effects and electrophysiology). It is also reassuring that these correct guesses did not compromise either the masking of the patients themselves, or the clinical raters (who were at chance level). Follow-up interviews revealed that these guesses were based on the immediate postintervention performance of patients on which MST and ECT differed markedly, especially for the time to recover orientation. A potential means of avoiding this confound in future studies would be to have a separate rater time the speed of reorientation, and only bring in the neuropsychological rater once the patient was fully reoriented. Therefore, the rater would be masked to the speed of reorientation and free from any bias those data might exert on subsequent testing.

The largely consistent cognitive advantages of MST relative to ECT support the role of current pathways and patterns of seizure expression in determining the effects of convulsive therapy. These initial results indicate that further clinical work with MST as a novel form of convulsive therapy is warranted. Future work will be needed to address the clinical efficacy of a full course of MST.

\section{ACKNOWLEDGEMENTS}

This work was presented in part at the 11th Annual Meeting of the Association for Convulsive Therapy, New Orleans, Louisiana, May 5, 2001. This work was supported in part by Grants K08 MH01577 (Dr Lisanby), R01 MH60884 (Dr Lisanby), and R01 MH35636 (Dr Sackeim) from the National Institute of Mental Health, Rockville, MD, a New Investigator Pilot Award from the Office of Clinical Trials of Columbia College of Physicians and Surgeons, a Distinguished Investigator Award from the National Alliance for Research in Schizophrenia and Depression (Dr Sackeim), and grants 4038-044046 and 3231-044523 from the Swiss National Science Foundation (Dr Schlaepfer). Thanks are due to Linda Fitzsimmons, RN, MS, Shoshana Peyser, PhD, Lisa M Barroilhet, BS, Eric Neufeld, BS, and Tarique Perera, $\mathrm{MD}$, for assistance with data collection and clinical care, and the patients and staff of the New York State Psychiatric Institute General Clinical Research Unit who participated in this study.

\section{REFERENCES}

Abrams R, Swartz CM, Vedak C (1991). Antidepressant effects of high-dose right unilateral electroconvulsive therapy. Arch Gen Psychiatry 48: 746-748.

American Psychiatric Association (2001). The Practice of ECT: Recommendations for Treatment, Training and Privileging, 2nd edn American Psychiatric Press: Washington, D.C..

Amiaz R, Stein O, Schreiber S, Danon PN, Dolberg OT, Grunhaus L (2001). Magnetic and seizure thresholds before and after six electroconvulsive treatments. J ECT 17: 195-197.

Awata S, Konno M, Kawashima R, Suzuki K, Sato T, Matsuoka H et al (2002). Changes in regional cerebral blood flow abnormalities in late-life depression following response to electroconvulsive therapy. Psychiatry Clin Neurosci 56: 31-40.

Bailine SH, Rifkin A, Kayne E, Selzer JA, Vital-Herne J, Blieka M et al (2000). Comparison of bifrontal and bitemporal ECT for major depression. Am J Psychiatry 157: 121-123.

Barker AT, Jalinous R, Freeston IL (1985). Non-invasive magnetic stimulation of human motor cortex. Lancet 1: 1106-1107.

Benton AL (1983). Multi-Lingual Aphasia Examination. AJA Associates: Iowa City.

Brasil-Neto JP, Cohen LG, Panizza M, Nilsson J, Roth BJ, Hallett M (1992). Optimal focal transcranial magnetic activation of the human motor cortex: effects of coil orientation, shape of the induced current pulse, and stimulus intensity. J Clin Neurophysiol 9: 132-136.

Burt T, Lisanby SH, Sackeim HA (2002). Neuropsychiatric applications of transcranial magnetic stimulation: a meta analysis. Int J Neuropsychopharmacol 5: 73-103.

Buschke H (1973). Selective reminding for analysis of memory and learning. J Verbal Learn Verbal Behav 12: 543-550.

Cabeza R, Anderson ND, Houle S, Mangels JA, Nyberg L (2000). Age-related differences in neural activity during item and temporal-order memory retrieval: a positron emission tomography study. J Cogn Neurosci 12: 197-206.

Cabeza R, Mangels J, Nyberg L, Habib R, Houle S, McIntosh AR et al (1997). Brain regions differentially involved in remembering what and when: a PET study. Neuron 19: 863-870.

Claussen J, Witte OW, Schlaug G, Seitz RJ, Holthausen H, Benecke R (1995). Epileptic seizures triggered directly by focal transcranial magnetic stimulation. Electroencephal Clin Neurophysiol 94: 19-25.

Conca A, Konig P, Hausmann A (2000). Transcranial magnetic stimulation induces 'pseudoabsence seizure'. Acta Psychiatr Scand 101: 246-248. 
Daniel WF, Crovitz HF (1983a). Acute memory impairment following electroconvulsive therapy. 1. Effects of electrical stimulus waveform and number of treatments. Acta Psychiatr Scand 67: 1-7.

Daniel WF, Crovitz HF (1983b). Acute memory impairment following electroconvulsive therapy. 2. Effects of electrode placement. Acta Psychiatr Scand 67: 57-68.

Daniel WF, Crovitz HF, Weiner RD (1987). Neuropsychological aspects of disorientation. Cortex 23: 169-187.

Delva NJ, Brunet D, Hawken ER, Kesteven RM, Lawson JS, Waldron JJ (2000). Electrical dose and seizure threshold: relations to clinical outcome and cognitive effects in bifrontal, bitemporal, and right unilateral ECT. J ECT 16: 361-369.

Devanand DP, Fitzsimons L, Prudic J, Sackeim HA (1995). Subjective side effects during electroconvulsive therapy. Convulsive Ther 11: 232-240.

Dhuna A, Gates J, Pascual-Leone A (1991). Transcranial magnetic stimulation in patients with epilepsy [see comments]. Neurology 41: 1067-1071.

Driscoll DA (1970). An investigation of a theoretical model of the human head with application to current flow calculations and EEG interpretation. Ph.d. Thesis, University of Vermont.

Epstein CM (1990). Localizing the site of magnetic brain stimulation in humans. Neurology 40: 666-670.

Folkerts H (1996). The ictal electroencephalogram as a marker for the efficacy of electroconvulsive therapy. Eur Arch Psychiatry Clin Neurosci 246: 155-164.

Garcia-Toro M, Pascual-Leone A, Romera M, Gonzalez A, Mico J, Ibarra $\mathrm{O}$ et al (2001). Prefrontal repetitive transcranial magnetic stimulation as add on treatment in depression. J Neurol Neurosurg Psychiatry 71: 546-548.

Geddes LA, Baker LE (1967). The specific resistance of biological material - a compendium of data for the biomedical engineer and physiologist. Med Biol Eng 5: 271-293.

George MS, Lisanby SH, Sackeim HA (1999). Transcranial magnetic stimulation: applications in neuropsychiatry. Arch Gen Psychiatry 56: 300-311.

George MS, Wassermann EM (1994). Rapid-rate transcranial magnetic stimulation and ECT [editorial]. Convulsive Ther 10: 251-254.

Goodglass H, Kaplan E (1983). The Assessment of Aphasia and Related Disorders, 2nd edn Lea \& Febiger: Philadelphia.

Gottesfeld BH, Lesse SM, Herskovitz H (1944). Studies in subconvulsive electric shock therapy effect of varied electrode applications. J Nerv Ment Dis 99: 56-64.

Gourovitch ML, Kirkby BS, Goldberg TE, Weinberger DR, Gold $\mathrm{JM}$, Esposito $\mathrm{G}$ et al (2000). A comparison of rCBF patterns during letter and semantic fluency. Neuropsychology 14: 353-360.

Hargrove EA, Bennett AE, Ford FR (1953). The value of subconvulsive electrostimulation in the treatment of some emotional disorders. Am J Psychiatry 109: 612-616.

Hayes KJ (1950). The current path in ECS. Arch Neurol Psychiatry 63: $102-109$.

Heilman K, Valenstein E (1993). Clinical Neuropsychology, 3rd edn Oxford University Press: New York.

Henry ME, Schmidt ME, Matochik JA, Stoddard EP, Potter WZ (2001). The effects of ECT on brain glucose: a pilot FDG PET study. J ECT 17: 33-40.

Hufnagel A, Elger CE (1991). Induction of seizures by transcranial magnetic stimulation in epileptic patients [letter]. J Neurol 238: 109-110.

Hufnagel A, Elger CE, Durwen HF, Boker DK, Entzian W (1990). Activation of the epileptic focus by transcranial magnetic stimulation of the human brain. Ann Neurol 27: 49-60.

Janowsky JS, Shimamura AP, Squire LR (1989). Source memory impairment in patients with frontal lobe lesions. Neuropsychologia 27: 1043-1056.
Kitabayashi Y, Ueda H, Tsuchida H, Iizumi H, Narumoto J, Nakamura K et al (2001). Relationship between regional cerebral blood flow and verbal fluency in Alzheimer's disease. Psychiatry Clin Neurosci 55: 459-463.

Krystal AD, Weiner RD, Coffey CE (1995). The ictal EEG as a marker of adequate stimulus intensity with unilateral ECT. $J$ Neuropsychiatry Clin Neurosci 7: 295-303.

Law SK (1993). Thickness and resistivity variations over the upper surface of the human skull. Brain Topography 6: 99-109.

Lerer B, Shapira B, Calev A, Tubi N, Drexler H, Kindler S et al (1995). Antidepressant and cognitive effects of twice- versus three-times-weekly ECT. Am J Psychiatry 152: 564-570.

Lezak MD (1995). Neuropsychological Assessment, 3rd edn Oxford University Press: New York.

Lisanby SH, Devanand DP, Nobler MS, Prudic J, Mullen L, Sackeim HA (1996). Exceptionally high seizure threshold: ECT device limitations. Convulsive Ther 12: 156-164.

Lisanby SH, Luber B, Finck AD, Schroeder C, Sackeim HA (2001a). Deliberate seizure induction with repetitive transcranial magnetic stimulation. Arch Gen Psychiatry 58: 199-200.

Lisanby SH, Luber B, Kwon E, Crupain M, Sackeim HA (2002). Physiological characteristics of magnetic seizure therapy (MST) induced seizures in nonhuman primates and patients with major depression. Biol Psychiatry 51: 43S.

Lisanby SH, Luber B, Nobler MS, Louie J, Prudic J, Devanand DP et al (1997). Dissociation between anticonvulsant effects of ECT and TMS motor threshold. American College of Neuropsychopharmacology 36th Annual Meeting Abstracts 256.

Lisanby SH, Luber BL, Schroeder C, Osman M, Finck D, Amassian VE et al (1998a). rTMS in primates: intracerebral measurement of rTMS and ECS induced voltage in vivo. Electroencephalogr Clin Neurophysiol 107: 79P.

Lisanby SH, Luber B, Schroeder C, Osman M, Finck D, Jalinous R et al (1998b). Intracerebral measurement of rTMS and ECS induced voltage in vivo. Biol Psychiatry 43: $100 \mathrm{~S}$.

Lisanby SH, Maddox JH, Prudic J, Devanand DP, Sackeim HA (2000). The effects of electroconvulsive therapy on memory of autobiographical and public events. Arch Gen Psychiatry 57: 581-590.

Lisanby SH, Moscrip T, Morales O, Luber BL, Schroederv C, Sackeim HA (in press) Neurophysiological Cahracterization of Magnetic Seizure Therapy (MST) in Nonhuman Primates. Clinical Neurophysiology.

Lisanby SH, Pascual-Leone A, Sampson SM, Boylan LS, Burt T, Sackeim HA (2001b). Augmentation of sertraline antidepressant treatment with transcranial magnetic stimulation. Biol Psychiatry 49: $81 \mathrm{~S}$.

Lisanby SH, Sackeim HA (2000). TMS in major depression. In: George MS, Belmaker RH (eds) Transcranial Magnetic Stimulation (TMS): Applications in Neuropsychiatry. American Psychiatric Press: Washington, DC. pp 185-200.

Lisanby SH, Sackeim HA (2002). Transcranial magnetic stimulation and electroconvulsive therapy: similarities and differences. In: Pascual-Leone A, Davey N, Rothwell J, Wassermann E, Puri BK (eds) Handbook of Transcranial Magnetic Stimulation. Arnold Publishers: London, UK. pp 376-395.

Lisanby SH, Schlaepfer TE, Fisch H-U, Sackeim HA (2001c). Magnetic seizure induction for the treatment of major depression. Arch Gen Psychiatry 58: 303-305.

Loo C, Mitchell P, Sachdev P, McDarmont B, Parker G, Gandevia S (1999). Double-blind controlled investigation of transcranial magnetic stimulation for the treatment of resistant major depression. Am J Psychiatry 156: 946-948.

Luber B, Nobler MS, Moeller JR, Katzman GP, Prudic J, Devanand DP et al (2000). Quantitative EEG during seizures induced by electroconvulsive therapy: relations to treatment modality and clinical features. II. Topographic analyses. J ECT 16: 229-243. 
Maccabee PJ, Amassian VE, Eberle LP, Rudell AP, Cracco RQ, Lai KS et al (1991). Measurement of the electric field induced in inhomogeneous volume conductors by magnetic coils: application to human spinal neurogeometry. Electroencephalogr Clin Neurophysiol 81: 224-237.

Maccabee PJ, Eberle L, Amassian VE, Cracco RQ, Rudell A, Jayachandra M (1990). Spatial distribution of the electric field induced in volume by round and figure ' 8 ' magnetic coils: relevance to activation of sensory nerve fibers. Electroencephalogr Clin Neurophysiol 76: 131-141.

Manes F, Jorge R, Morcuende M, Yamada T, Paradiso S, Robinson RG (2001). A controlled study of repetitive transcranial magnetic stimulation as a treatment of depression in the elderly. Int Psychogeriatr 13: 225-231.

Martin JL, Barbanoj MJ, Schlaepfer TE, Clos S, Perez V, Kulisevsky $J$ et al (2002). Transcranial magnetic stimulation for treating depression. Cochrane Database Syst Rev, CD003493.

McCall WV, Reboussin DM, Weiner RD, Sackeim HA (2000). Titrated moderately suprathreshold vs fixed high-dose right unilateral electroconvulsive therapy: acute antidepressant and cognitive effects. Arch Gen Psychiatry 57: 438-444.

McElhiney MC, Moody BJ, Steif BL, Prudic J, Devanand DP, Nobler MS et al (1995). Autobiographical memory and mood: effects of electroconvulsive therapy. Neuropsychology 9: 501-517.

Mesulam MM (1985). In: Davis FA (ed) Principles of Behavioral Neurology. Philadelphia.

Mills KR, Boniface SJ, Schubert M (1992). Magnetic brain stimulation with a double coil: the importance of coil orientation. Electroencephalogr Clin Neurophysiol 85: 17-21.

Morris AJ, Roche SA, Bentham P, Wright J (2002). A dental risk management protocol for electroconvulsive therapy. J ECT 18: 84-89.

Mosimann UP, Marre SC, Werlen S, Schmitt W, Hess CW, Fisch HU et al (2002). Antidepressant effects of repetitive transcranial magnetic stimulation in the elderly: correlation between effect size and coil-cortex distance. Arch Gen Psychiatry 59: 560-561.

Ng C, Schweitzer I, Alexopoulos P, Celi E, Wong L, Tuckwell V et al (2000). Efficacy and cognitive effects of right unilateral electroconvulsive therapy. J ECT 16: 370-379.

Nobler MS, Luber B, Moeller JR, Katzman GP, Prudic J, Devanand DP et al (2000). Quantitative EEG during seizures induced by electroconvulsive therapy: Relations to treatment modality and clinical features. I. Global analyses. J ECT 16: $211-228$.

Nobler MS, Oquendo MA, Kegeles LS, Campbell C, Sackeim HA, Mann JJ (2001). Decreased regional brain metabolism after ECT. Am J Psychiatry 158: 305-308.

Nobler MS, Sackeim HA, Prohovnik I, Moeller JR, Mukherjee S, Schnur DB et al (1994). Regional cerebral blood flow in mood disorders, III. Treatment and clinical response. Arch Gen Psychiatry 51: 884-897.

Nobler MS, Sackeim HA, Solomou M, Luber B, Devanand DP, Prudic J (1993). EEG manifestations during ECT: effects of electrode placement and stimulus intensity. Biol Psychiatry 34: 321-330.

Nyberg L, McIntosh AR, Cabeza R, Habib R, Houle S, Tulving E (1996). General and specific brain regions involved in encoding and retrieval of events: what, where, and when. Proc Natl Acad Sci USA 93: 11280-11285.

Pascual-Leone A, Houser CM, Reese K, Shotland LI, Grafman J, Sato $S$ et al (1993). Safety of rapid-rate transcranial magnetic stimulation in normal volunteers. Electroencephalogr Clin Neurophysiol 89: 120-130.

Pihlajamaki M, Tanila H, Hanninen T, Kononen M, Laakso M, Partanen K et al (2000). Verbal fluency activates the left medial temporal lobe: a functional magnetic resonance imaging study. Ann Neurol 47: 470-476.
Prudic J, Peyser S, Sackeim HA (2000). Subjective memory complaints: a review of patient self-assessment of memory after electroconvulsive therapy. J ECT 16: 121-132.

Prudic J, Sackeim HA, Decina P, Hopkins N, Ross FR, Malitz S (1987). Acute effects of ECT on cardiovascular functioning: relations to patient and treatment variables. Acta Psychiatr Scand 75: 344-351.

Prudic J, Sackeim HA, Devanand DP, Krueger RB, Settembrino JM (1994). Acute cognitive effects of subconvulsive electrical stimulation. Convulsive Ther 10: 4-24.

Reutens DC, Berkovic SF (1992). Increased cortical excitability in generalised epilepsy demonstrated with transcranial magnetic stimulation [letter]. Lancet 339: 362-363.

Roth BJ, Pascual-Leone A, Cohen LG, Hallet M (1992). The heating of metal electrodes during rapid-rate magnetic stimulation: a possible safety hazard. Electroencephalogr Clin Neurophysiol 85: $116-123$.

Rush S, Driscoll D (1968). Current distribution in the brain from surface electrodes. Anesth Anal 47: 717-723.

Sackeim HA (1992). The cognitive effects of electroconvulsive therapy. In: Moos WH, Gamzu ER, Thal LJ (eds) Cognitive Disorders: Pathophysiology and Treatment. Marcel Dekker: New York. pp 183-228.

Sackeim HA (1994). Magnetic stimulation therapy and ECT. Convulsive Ther 10: 255-258.

Sackeim HA, Decina P, Kanzler M, Kerr B, Malitz S (1987a). Effects of electrode placement on the efficacy of titrated, low-dose ECT. Am J Psychiatry 144: 1449-1455.

Sackeim HA, Decina P, Prohovnik I, Malitz S (1987b). Seizure threshold in electroconvulsive therapy. Effects of sex, age, electrode placement, and number of treatments. Arch Gen Psychiatry 44: 355-360.

Sackeim HA, Decina P, Prohovnik I, Portnoy S, Kanzler M, Malitz S (1986a). Dosage, seizure threshold, and the antidepressant efficacy of electroconvulsive therapy. Ann NY Acad Sci 462: 398-410.

Sackeim HA, Long J, Luber B, Moeller JR, Prohovnik I, Devanand DP et al (1994). Physical properties and quantification of the ECT stimulus: I. Basic principles. Convulsive Ther 10: 93-123.

Sackeim HA, Luber B, Katzman GP, Moeller JR, Prudic J, Devanand DP et al (1996). The effects of electroconvulsive therapy on quantitative electroencephalograms. Relationship to clinical outcome. Arch Gen Psychiatry 53: 814-824.

Sackeim HA, Luber B, Moeller JR, Prudic J, Devanand DP, Nobler MS (2000a). Electrophysiological correlates of the adverse cognitive effects of electroconvulsive therapy. J ECT 16: 110-120.

Sackeim HA, Portnoy S, Neeley P, Steif BL, Decina P, Malitz S (1986b). Cognitive consequences of low-dosage electroconvulsive therapy. Ann NY Acad Sci 462: 326-340.

Sackeim HA, Prudic J, Devanand DP, Kiersky JE, Fitzsimons L, Moody BJ et al (1993). Effects of stimulus intensity and electrode placement on the efficacy and cognitive effects of electroconvulsive therapy. $N$ Engl J Med 328: 839-846.

Sackeim HA, Prudic J, Devanand DP, Nobler MS, Lisanby SH, Peyser S et al (2000b). A prospective, randomized, double-blind comparison of bilateral and right unilateral electroconvulsive therapy at different stimulus intensities. Arch Gen Psychiatry 57: 425-434.

Sackeim HA, Prudic J, Nobler MS, Lisanby SH, Devanand DP, Peyser S (2001). Ultra-brief pulse ECT and the affective and cognitive consequences of ECT. J ECT 17: 77.

Sackeim HA, Ross FR, Hopkins N, Calev L, Devanand DP (1987c). Subjective side effects acutely following ECT: associations with treatment modality and clinical response. Convulsive Ther 3: 100-110.

Shimamura AP, Squire LR (1987). A neuropsychological study of fact memory and source amnesia. J Exp Psychol Learn Mem Cogn 13: $464-473$. 
Silfverskiöld P, Risberg J (1989). Regional cerebral blood flow in depression and mania. Arch Gen Psychiatry 46: 253-259.

Smitt JW, Wegener CF (1944). On electric convulsive therapy with particular regard to a parietal application of electrodes, controlled by intracerebral voltage measurements. Acta Psychiatr Neurol 19: 529-549.

Sobin C, Sackeim HA, Prudic J, Devanand DP, Moody BJ, McElhiney MC (1995). Predictors of retrograde amnesia following ECT. Am J Psychiatry 152: 995-1001.

Spreen O, Strauss E (1998). A Compendium of Neuropsychological Tests: Administration, Norms, and Commentary. Oxford University Press: New York.

Suppes T, Webb A, Carmody T, Gordon E, Gutierrez-Esteinou R, Hudson JI et al (1996). Is postictal electrical silence a predictor of response to electroconvulsive therapy? J Affect Disord 41: 55-58.

Tassinari CA, Michelucci R, Forti A, Plasmati R, Troni W, Salvi F et al (1990). Transcranial magnetic stimulation in epileptic patients: usefulness and safety. Neurology 40: 1132-1133.
Ulett G, Smith K, Gleser G (1956). Evaluation of convulsive and subconvulsive shock therapies utilizing a control group. Am J Psychiatry 112: 795-802.

Vallar G (1993). The anatomical basis of spatial hemineglect in humans. In: Robertson IH, Marshall JC (eds) Unilateral Neglect: Clinical and Experimental Studies. Lawrence Erlbaum Associates: Hillsdale. pp 27-62.

Wassermann EM (1998). Risk and safety of repetitive transcranial magnetic stimulation: report and suggested guidelines from the International Workshop on the Safety of Repetitive Transcranial Magnetic Stimulation, June 5-7, 1996. Electroencephalogr Clin Neurophysiol 108: 1-16.

Wassermann EM, Cohen LG, Flitman SS, Chen R, Hallett M (1996). Seizures in healthy people with repeated 'safe' trains of transcranial magnetic stimuli. Lancet 347: 825-826.

Wassermann EM, Lisanby SH (2001). Therapeutic application of repetitive transcranial magnetic stimulation: a review. Clin Neurophysiol 112: 1367-1377.

Weaver L, Williams R, Rush S (1976). Current density in bilateral and unilateral ECT. Biol Psychiatry 11: 303-312. 